\title{
O Comitê de Ética em Pesquisa (CEP) e as Publicações Científicas
}

\author{
Cristina Muccioli
}

A publicação de trabalho cientifico é o estágio final de toda a pesquisa. Pesquisa realizada e não publicada, não é divulgada e, portanto, não se torna disponível para a comunidade científica ou população leiga e é igual à pesquisa não realizada.

Todo o processo de realização da pesquisa inicia-se da inquietude intelectual do pesquisador que, a partir de uma dúvida ou uma idéia decide realizar um trabalho científico para responder a suas dúvidas ou viabilizar a sua idéia. Tal processo, além de muito trabalhoso, deve seguir normas rígidas cientificas e éticas para que possa ser realizado.

De acordo com a Resolução 196/96 do Conselho Nacional de Saúde (CNS), Pesquisa Clínica é definida como pesquisa envolvendo seres humanos; a que, individual ou coletivamente, envolva o ser humano, de forma direta ou indireta, em sua totalidade ou partes dele, incluindo o manejo de informações ou materiais.

A Pesquisa Clínica é o estudo sistemático que segue métodos científicos aplicáveis aos seres humanos, denominados voluntários, ou "sujeitos de pesquisa". Quando realizada com medicamentos tem o objetivo de verificar efeitos, analisar absorção, distribuição, metabolismo e excreção com finalidade de estabelecer eficácia e segurança do produto.

A Pesquisa Clínica realizada para o desenvolvimento de novos fármacos é um processo longo, trabalhoso, de custo muito elevado (média de 10 a 12 anos com custo de $300 \mathrm{mi}-$ lhões de dólares).

A fase Pré-Clínica é a realização dos estudos "in vitro" para testar a atividade farmacológica e segurança do produto. Geralmente, nessa fase, $90 \%$ deles são eliminados. Se a atividade farmacológica especifica perfil de toxidade aceitável então pode-se prosseguir à Fase I.

Na Fase I são iniciados os testes em seres humanos, geralmente voluntários sadios, para testar segurança e tolerabilidade do produto. Parâmetros farmacológicos, biodisponibilidade, dose e posologia também são analisados nessa fase, que conta com pequeno número de voluntários (de 20 a 100 indivíduos).

A Fase II é aquela em que é realizada a Pesquisa terapêutica piloto para determinar segurança e eficácia do princípio ativo, em curto prazo, em voluntários que apresentem a doença a ser estudada (tratada). Essa fase é importante para estabelecer o intervalo adequado entre as doses e regimes de administração do novo fármaco. Geralmente conta com número maior de voluntários doentes (entre 100 a 300). De acordo com os resultados da relação dose-resposta pode ser programado o estudo de Fase III.
Na Fase III é realizada a pesquisa terapêutica aplicada em número elevado de portadores da enfermidade. Análise de risco/benefício do princípio ativo a curto prazo, estudo dos eventos adversos, interações medicamentosas, fatores modificadores do efeito (ex: sexo, idade, raça) são analisados nesta fase. Nela, são também analisadas as condições normais da droga em estudo e após seu término é feita a aprovação para uso comercial. Participam geralmente entre 300 a mais de 1000 indivíduos.

A Fase IV conhecida como Pesquisa Pós-comercialização visa detectar reações adversas inesperadas e determinar efeitos a longo prazo. É também nessa fase que pode ser feita a avaliação do medicamento em outras populações. Também é possível estudar novos usos para o novo fármaco. Nesse caso, a pesquisa deve ser reiniciada a partir da fase II. O número de participantes geralmente não é especificado (mais ou menos 10.000 voluntários). Essa fase é muito importante para estudos de farmacovigilância.

É importante ressaltar que, para todo e qualquer tipo de pesquisa a ser realizado, após o desenho do estudo deve ser feito o encaminhamento do protocolo de pesquisa para o Comitê de ética da Instituição e, apenas após aprovação do protocolo é que o estudo pode ser realizado. Isto é válido não só para pesquisa com seres humanos, como para pesquisa experimental, revisão de prontuários, análise retrospectiva, análise anatomo-patológica, levantamento genético, levantamento social, levantamento epidemiológico e pesquisas envolvendo somente questionários, entre outros.

O Comitê de Ética em Pesquisa (CEP) é um colegiado interdisciplinar e independente, com "munus público", que deve existir nas instituições que realizam pesquisas envolvendo seres humanos no Brasil, criado para defender os interesses dos sujeitos da pesquisa em sua integridade e dignidade e para contribuir no desenvolvimento da pesquisa dentro dos padrões éticos (Normas e Diretrizes Regulamentadoras da Pesquisa Envolvendo Seres Humanos - Resolução CNS 196/96, II.4).

O CEP é responsável pela avaliação e acompanhamento dos aspectos éticos de todas as pesquisas envolvendo seres humanos. Este papel está bem estabelecido nas diversas diretrizes éticas internacionais (Declaração de Helsinque, Diretrizes Internacionais para as Pesquisas Biomédicas envolvendo Seres Humanos - CIOMS) e Brasileiras (Resolução CNS 196/ 96 e complementares), diretrizes estas que ressaltam a necessidade de revisão ética e científica de pesquisa envolvendo seres humanos, visando salvaguardar a dignidade, os direitos, a segurança e o bem estar do sujeito de pesquisa. Além 
disso, o CEP contribui para a qualidade das pesquisas e para a discussão do papel da pesquisa no desenvolvimento institucional e social da comunidade.

Muito importante também é a contribuição do CEP exercendo papel consultivo e, em especial, papel educativo para assegurar a formação continuada dos pesquisadores da instituição e promover a discussão dos aspectos éticos das pesquisas em seres humanos na comunidade.

Portanto, de acordo com a Resolução CNS 196/96, "toda pesquisa envolvendo seres humanos deverá ser submetida à apreciação de um CEP”. O CEP irá então analisar os projetos recebidos e deverá emitir parecer em período máximo de 30 dias. Após análise do protocolo pelo CEP, este deverá obedecer ao fluxograma para pesquisas envolvendo seres humanos.

Projetos envolvendo seres humanos serão classificados em três diferentes grupos (I, II, III), de acordo com seu conteúdo. Baseado no plano do projeto, o CEP deverá fazer a classificação correta e seguir os fluxos determinados.

Projetos do Grupo I (áreas temáticas especiais) deverão ser enviados para a Comissão Nacional de Ética em Pesquisa (CONEP) e só poderão ser iniciados após a aprovação feita por esse órgão.

Projetos do Grupo II deverão ser enviados para a CONEP somente para conhecimento e acompanhamento.

Projetos do Grupo III deverão ser enviados para a CONEP trimestralmente somente para conhecimento e acompanhamento.

A CONEP é uma comissão assessora do Conselho Nacional de Saúde, criada pela Resolução 196/96 com a função de implementar as normas e diretrizes regulamentadoras de pesquisa envolvendo seres humanos. Tem função consultiva, deliberativa, normativa e educativa, atuando conjuntamente com uma rede de CEPs, organizados em diferentes instituições e outras instâncias.

Esse fluxograma deve ser seguido rigorosamente e respeitado toda vez que se pretende fazer pesquisa. Esta é uma forma de garantir que todo o processo seja realizado de acordo com as regulamentações universais de ética em pesquisa.

Da mesma forma, acredita-se que todo trabalho enviado para publicação tenha sido submetido a essas mesmas regras éticas descritas anteriormente. Os editores das diversas revistas científicas que são indexadas em bases de dados nacionais e internacionais e que contam com "peer review", geralmente incluem nas suas normas de publicações a necessidade de que o trabalho enviado para a publicação tenha sido submetido à aprovação de um comitê de ética em pesquisa. Algumas revistas indexadas no "Medline" e que estão entre as "Top 10" na classificação das melhores em publicações científicas, exigem o encaminhamento de carta de aprovação do CEP Institucional para os artigos científicos enviados para serem submetidos à análise dos revisores e carta com assinatura do Termo de Consentimento Livre e Esclarecido dos pacientes no caso de relato de caso clínico.

Essas regras dão origem a alguns questionamentos, que podem ser tema de outro editorial, que são: quem é o responsável pela veracidade das informações referentes à aprovação do CEP? Somente os autores, ou os editores também deveriam ser responsabilizados e exigirem a apresentação das cartas de aprovação? As revistas científicas podem ser responsabilizadas pelas informações publicadas?

Este editorial tem a finalidade e a responsabilidade de esclarecer e de informar sobre alguns temas importantes relacionados à ética em publicação científica e esclarece que os editores dos Arquivos Brasileiros de Oftalmologia têm respeitado todas essas regras ao máximo!

\section{4" JORNADA GAUCHA DE oftalmologia}

\section{2 a 24 de outubro de 2004 Hotel Laje de Pedra - Canela - RS}

Informações: salalrum@terra.com.br 